\title{
REFERENCES
}

Budd, W. F., and others. 1971. Derived physical characteristics of the Antarctic ice sheet. Mark I, by W. F. Budd, D. Fenssen, and $U$. Radok. Melbourne, University of Melbourne. Meteorology Dept. (University of Melbourne. Meteorology Dept., Publication No. 18.)

Clark, J. A., and others. 1978. Global changes in post-glacial sea level: a numerical calculation, by J. A. Clark, W. E. Farrell, and W. R. Peltier. Quaternary Research, Vol. 9, No. 3, p. $265-87$.

Sugden, D. E. 1977. Reconstruction of the morphology, dynamics, and thermal characteristics of the Laurentide ice sheet at its maximum. Arctic and Alpine Research, Vol. 9, No. I, p. 21-47.

Weertman, J. 1957. On the sliding of glaciers. Fournal of Glaciology, Vol. 3, No. 21, p. 33-38.

Weertman, J. 1978. Creep laws for the mantle of the Earth. Philosophical Transactions of the Royal Society of London, Ser. A, Vol. 288, No. I350, p. 9-26.

\section{ISOSTATIC EQUILIBRIUM GROUNDING LINE BETWEEN THE WEST ANTARGTIC IGE SHEET AND THE ROSS ICE SHELF}

\author{
By C. R. Bentley and L. Greischar \\ (Geophysical and Polar Research Center, University of Wisconsin, Madison, Wisconsin 537o6, \\ U.S.A.)
}

Abstract. Taking various retreat-rates for the presumed grounded ice sheet in the Ross embayment during Wisconsin time, as calculated by Thomas (Thomas and Bentley, 1978), and assuming a time constant of 4400 years for isostatic rebound, a sea-floor uplift of $100 \pm 50 \mathrm{~m}$ still to be expected in the grid western part of the Ross Ice Shelf can be calculated. The expected uplift diminishes from grid west to grid east, and is probably negligible in the eastern half of the shelf area. There are extensive areas near the present grounding line where the water depth beneath the shelf is less than roo m, so that uplift would lead to grounding. As grounding occurred, the neighboring ice shelf would thicken, causing grounding to advance farther. This process would probably extend the grounding line to a position running grid north-eastward across the shelf from the seaward end of Roosevelt Island, deeply indented by the extensions of the present ice streams. Floating ice would remain in the grid south-eastern half of the shelf.

\section{REFERENCE}

Thomas, R. H., and Bentley, C. R. 1978. A model for Holocene retreat of the West Antarctic ice sheet. Quaternary Research, Vol. 10, No. 2, p. $150-70$.

\section{A NUMERIGAL INVESTIGATION OF THE LARGE SGALE DYNAMIGS OF SEA IGE}

\author{
By W. D. Hibler III* \\ (U.S. Army Cold Regions Research and Engineering Laboratory, Hanover, New \\ Hampshire 03755, U.S.A.)
}

Abstract. Several numerical simulations of the Arctic ice cover over a seasonal cycle are carried out. Two different types of constitutive laws are examined: rigid plastic and linear viscous. In both cases, the strength of the ice interaction is taken as a function of ice thickness

* Numerical simulations performed while on leave as a Visiting Fellow, Geophysical Fluid Dynamics Program, Princeton University, Princeton, New Jersey. 
and compactness. The thickness and compactness, in turn, evolve according to continuity equations which include thermodynamic source and sink terms. The simulations with the rigid-plastic law reproduce reasonable geographical ice-thickness variations, ice outflow, and ice-velocity characteristics. The viscous simulations (especially the Newtonian viscous case) produce less satisfactory geographical ice thickness variations, and near-shore velocity characteristics. In addition the Newtonian-viscous simulation produces highly unrealistic ice-edge effects in summer. The results are discussed in terms of the relative magnitudes of the shear and compressive strengths, and in terms of the non-linear versus linear dependence on deformation in the ice rheology. The portion of this study employing a plastic constitutive law is published in full in Journal of Physical Oceanography, Vol. 9, No. 4, 1979, p. 815-46.

\section{DISCUSSION}

W. F. Budd: How well have you simulated the ocean heat and salt exchanges under the ice and in the basin as a whole?

W. D. Hibler III: These effects are crudely incorporated by using ice growth-rates dependent on ice thickness and season. The growth-rates in turn were largely based on Maykut and Untersteiner's calculations where these exchanges were parameterized by a constant upward oceanic heat flux. Clearly improvements in the treatment of such oceanic effects are needed.

V. R. Neralla: What is the grid distribution used for your numerical simulation? I wonder how your model responds if one applies it to real-time, short-range, small-scale prediction problems?

Hibler: The grid size used in the simulation was $125 \mathrm{~km}$. I have not applied it to smaller time and space scale problems. However, the comparisons done here between linear-viscous, Newtonian-viscous, and plastic rheologies, strongly suggest that the non-linear plastic rheology is substantially better; a statement that I expect will also hold up on finer scales. Moreover, using my numerical scheme, the momentum balance with a non-linear rheology can be solved almost as simply and efficiently as with a linear-viscous rheology.

R. S. PRITchard: What unconfined compressive strength causes arching across the Greenland Strait under typical loads?

Hibler: The reduction of outflow in the Greenland-Spitsbergen passage is not a question of arching, but simply a reduction of flow due to using a rheology which allows higher shear stresses to develop. For the plastic case, doubling the shear strength (i.e. the deviatoric stress allowable for pure shearing deformation) reduces the outflow by $30 \%$. You might get at the problem analytically by assuming a typical outflow velocity field and then plotting the stress state.

\section{PREDIGTING THE MOTIONS OF DRIFTING OPEN PAGK IGE}

\section{By Uri Feldman}

(Atmospheric Environment Service, Aerospace Meteorology Division, 4905 Dufferin Street, Downsview, Ontario $\mathrm{M}_{3} \mathrm{H}_{5} \mathrm{~T}_{4}$, Canada)

and Philip J. Howarth

(Department of Geography, McMaster University, Hamilton, Ontario L8S ${ }_{4} \mathrm{~K} \mathrm{r}$, Canada)

Abstract. Methods based on remotely-sensed data are needed to predict motions of drifting open pack ice and to determine sea-ice parameters associated with these motions. The method presented here is able: 